\title{
El antihaitianismo en la República Dominicana: ¿un giro biopolítico?
}

\author{
Anti-Haitianism in the Dominican Republic: \\ A bio-political spin?
}

\section{Samuel Martínez* \\ Bridget Wooding ${ }^{\star \star}$}

Resumen. La Sentencia 168, sentencia del 23 de septiembre de 2013, dictada por la máxima instancia de justicia de la República Dominicana, el Tribunal Constitucional, ha sido comúnmente representada como un decreto que expulsa de la República Dominicana a todos los residentes haitianos no autorizados, y además despoja de la ciudadanía a aquellos nacidos en la República Dominicana de padres haitianos. Sin embargo, en conjunto, la evidencia es que la sentencia no busca la exclusión territorial de los haitianos y los descendientes de haitianos tanto como su inclusión en la economía política dominicana como ciudadanos de segunda clase, inmovilizándolos durante el tiempo que sea conveniente dentro de una subclase de carácter hereditario. Después de la sentencia, los antiguos «excesos» (de intimidación y expulsión masiva) han continuado y posiblemente empeorado. Pero más escalofriante aún es la adición de una reciente exclusión social legalizada y burocratizada. Los objetivos siguen siendo evidentemente antihaitianos. Sin embargo, lo que se busca no es expulsar a los descendientes de haitianos ni limitarlos visiblemente detrás de las alambradas, sino disuadirlos de acumular invisiblemente el capital humano, las credenciales económicas y los documentos de ciudadanía necesarios para aspirar a las comodidades y el respeto de la clase media. La sentencia señala así el cambio de un régimen señorial a un modo biopolítico de gobierno de grupos minoritarios, basado en el uso de nuevas tecnologías legales y de almacenamiento y recuperación de información. De esta manera, el nuevo modo biopolítico de exclusión anti-haitiana encaja mejor que el anterior con formas más variadas y flexibles de incorporación del trabajo haitiano a la economía neoliberal.

Palabras clave. República Dominicana, derechos humanos, derechos de las minorías, derechos de los migrantes, biopolítica, domínico-haitianos, inmigrantes haitianos

\begin{abstract}
Sentence 168, handed down on the 23 September 2013 by the highest court of justice in the Dominican Republic, the Constitutional Tribunal, has been commonly depicted as the decree that expelled all unauthorized Haitian residents from the Dominican Republic, and further stripped the citizenship of those born in the Dominican Republic of Haitan parents. However, the overall evidence suggests that the Sentence did not seek the territorial exclusion of Haitians and their descendents so much as their inclusion in Dominican political economy as second-class citizens, paralyzing them for a convenient period within a hereditary sub-class. After the Sentence, the old "excesses» (of intimidation and mass explusion) have continued and possibly become worse. But even more chilling is the addition of a recent legal and bureaucratic social exclusion. The aims continue to be clarly anti-Haitian. However, the goal is not to expel the descendents of Haitians nor visibly fence them in, but rather to dissuade them from silently accumultating human capital, economic credentials and the necessary citizenship documents in order to aspire to the comfort and respectability of the middle class. The Sentence thus indicated a change in a feudal system toward a bio-political mode of governance over minority groups, based on the use of new, legal, technologies and the mass storage and recovery of information. Thus, the new anti-Haitian biopolitical mode of exclusion is more capable of using a greater variety and more flexible ways of incorporating Haitian labor into the neoliberal economy.
\end{abstract}

Keywords. Dominican Republic, human rights, minority rights, migrant rights, bio-politics, DominicanHaitian, Haitian immigrants.

\author{
*Universidad de Connecticut \\ ${ }^{* *}$ Centro para la Observación Migratoria y el Desarrollo Social en el Caribe)
}



La República Dominicana dio un nuevo giro legal en el manejo de la situación de los inmigrantes haitianos y los dominicanos de ascendencia haitiana. Gran parte del mundo se enteró por primera vez de los importantes acontecimientos que se desarrollaban en las relaciones de este estado caribeño con su vecino República de Haití el 23 de septiembre de 2013, cuando la Sentencia 168 del Tribunal Constitucional fue muy censurada por haber ordenado la expulsión de los inmigrantes haitianos no autorizados y la anulación de la ciudadanía de los dominicanos nacidos de padres que no residieron legalmente en el país. Aunque no se discutió mucho en ese momento, la sentencia no fue un acontecimiento repentino o aislado, fue más bien la culminación de un proceso de diez años de reforma legal anti-haitiana: desde principios de la década de 2000 se había forjado una nueva política de inmigración y ciudadanía, misma que fue enarbolada y expandida por la sentencia.

En este artículo se sostiene, primeramente que una juridicalización reaccionaria del exclusionismo antihaitiano ya estaba en marcha en la República Dominicana años antes de la Sentencia 168. Cabe denominar al proceso «juridicalización» porque la ley y los procedimientos burocráticos están suplantando el poder arbitrario como el medio principal para contener la libre movilidad, y las aspiraciones de ascenso socioeconómico de los haitianos y descendientes de haitianos. Dirigidos hacia objetivos reaccionarios son los mismos procesos legales en los que creen firmemente los guardianes de los derechos humanos a nivel internacional: la deliberación legislativa, la autoridad en los tribunales de justicia y el rechazo de la discriminación arbitraria a favor de procedimientos aparentemente no discriminatorios. Una especie de mimetismo inverso de los principios internacionales de derechos humanos de la no discriminación está al descubierto, por ejemplo, en la ausencia de las palabras «Haití» o «haitiano» en los instrumentos jurídicos de la última década. Este es el prejuicio modernizado, que se implementa mediante la aplicación de un barniz de normatividad legal sobre una arquitectura preexistente de exclusiones étnicas y raciales.

En segundo lugar, la juridicalización reaccionaria es algo más que el revestimiento de la xenofobia que antes era en gran parte informal, además ha traído cambios sustantivos, que caracterizamos como un giro biopolítico. Algo que marca el giro legal como un fenómeno «biopolítico» es que asume como objetivo hacer que la exclusión antihaitiana funcione menos a través de la vigilancia, la dominación violenta y el confinamiento físico o expulsión territorial de individuos, y más a través de la gestión pública, el almacenamiento computarizado de 
los registros civiles y la clasificación de poblaciones en una jerarquía de grupos desigualmente dotados por ley. Este giro biopolítico se ajusta a las demandas laborales más flexibles de la economía neoliberal de la República Dominicana; a los haitianos y los dominicanos de ascendencia haitiana ya no se les tratará de guardar dentro de los enclaves de exportación, sino que serán confinados socioeconómicamente, a perpetuidad, a un estado civil deteriorado y una posición económica hiper-explotable.

Nada de lo anterior tiene como finalidad minimizar la incertidumbre y la preocupación que la sentencia desencadenó entre los inmigrantes haitianos del país y los dominicanos de ascendencia haitiana. La resolución de la sentencia desencadenó expresiones justificadas de indignación entre dichas poblaciones y los partidarios de derechos liberales en el país y en el extranjero. A pesar de esta oposición pública y de la sociedad civil, la sentencia ha sido interpretada como vinculante tanto por el Ejecutivo Dominicano como por la legislatura, la cual respondió con amplias reformas de inmigración y nacionalidad; asimismo hace referencia a un caso que había sido presentado por una dominicana de ascendencia haitiana, Juliana Deguis Pierre (República Dominiana, Tribunal Constitucional 2013). Ella cuestionó la constitucionalidad de un edicto burocrático, ampliamente conocido como la Resolución 12/07, que ordena a las oficinas de registro civil dominicano a que se nieguen a expedir documentos oficiales a personas nacidas en República Dominicana, cuyos padres no ciudadanos no presentaron documentos oficiales de identidad dominicanos al registro del nacimiento de los hijos. Deguis, nacida en 1984 en la República Dominicana, hija de padres haitianos, había ido a una oficina de registro civil en 2008 con su partida de nacimiento para solicitar una Cédula de Identidad y Electoral, la tarjeta de identidad nacional requerida para una amplia gama de funciones legales y administrativas en la República Dominicana. En la oficina de registro, los funcionarios incautaron su certificado de nacimiento y se negaron a expedir la tarjeta de identidad. La sentencia rechazó la solicitud de Deguis de que se le devolviera su certificado de nacimiento original y de que se renovaran sus documentos de identidad dominicanos.

La sentencia del Tribunal Constitucional fue más allá, no sólo generalizando su decisión a todos los individuos en una situación como la de Deguis, sino también pronunciándose sobre asuntos que ni siquiera fueron discutidos en su caso. De igual forma, ordenó a varias ramas del gobierno que diseñaran y coordinaran esfuerzos para resolver el estatus de ciudadanía de los dominicanos de 
ascendencia haitiana, como Deguis, y los derechos de residencia de los ciudadanos haitianos indocumentados.

No sólo el alcance y los modos de reforma previstos por la Sentencia 168 eran nuevos. La sentencia - junto con las leyes que respondieron a sus directivas mediante el establecimiento de procedimientos para regularizar la residencia de extranjeros residentes no autorizados y la nacionalidad de los dominicanos descendientes de inmigrantes irregulares - constituye algo nuevo en la escena dominicana. Tampoco marca un retroceso al impulso genocida del «corte» de 1937 (la masacre ordenada por Trujillo en la frontera dominicana con Haití), sino una progresión en una nueva política de la República Dominicana hacia sus inmigrantes y su minoría haitiana, que conlleva la aplicación de la tecnología al control individual de la identidad y la división de la sociedad en segmentos que merecen protección estatal o abandono (Ajana, 2013:2). Michel Foucault utiliza el término biopolítica para hablar de cambios como éste, que empezaron a transformar el concepto de "población» y las ideas sobre el gobierno en los estados industrializados de Europa entre finales del siglo XVIII y principios del siglo XIX (Virno, 2004:81). El giro biopolítico destaca una disminución en el derecho del soberano a tomar vida o dejar vivir y un aumento en el papel del gobierno en orquestar la distribución desigual de recursos de vida entre la ciudadanía.

En la República Dominicana de hoy se proclama la defensa de la soberanía como justificación de las reformas puestas en marcha por la Sentencia 168, si bien esas reformas marcan el paso a un nuevo estilo de control migrante/minoritario, más adecuado a una economía política neoliberal. El viejo estilo de control se emblematizaba por el espectáculo de la «esclavitud azucarera dominicana", nombre siempre inapropiado en la medida en que pocos braceros azucareros fueron cautivos, en todo caso se trataba de un régimen señorial, donde una soberanía extensa fue concedida por el estado a los productores azucareros. En las naciones, que antes de la reforma neoliberal eran las plantaciones azucareras, los jefes de las compañías eran soberanos menores, que ejercían la vigilancia directa y el control sobre los migrantes a través de los guardias de la compañía y supervisores de nivel inferior. El declive de la producción azucarera durante los 1990 y 2000 disminuyó las barreras geográficas a la movilidad que anteriormente limitaba a los inmigrantes haitianos y a los descendientes haitianos a las plantaciones azucareras y otros enclaves económicos. En su lugar, un nuevo sistema de control, esbozado por la Sentencia 168, busca instalar vallas institucionales para restringir la movilidad socioeconómica de los inmigrantes haitianos y los 
dominicanos de ascendencia haitiana. Lo que el nuevo sistema de control intenta bloquear no es la huida geográfica de las plantaciones, sino el escape socioeconómico de la pobreza y el trabajo pesado que se ejecutaría mediante un anhelado ascenso a la clase media por personas profesionalmente calificadas.

Bloquear la movilidad socioeconómica implica aparte de una vigilancia policial en los puntos de control de carreteras, el establecimiento de sistemas de información que posibiliten a los burócratas seleccionar quién obtenga acceso a qué tipo de documentos $y$, con eso, quién obtenga qué tipo de oportunidades económicas. Cercas invisibles de discapacidad burocrática son proyectadas por medio de la sentencia y su posterior legislación, para convertirse algún día en una forma de control del obrero haitiano que elimine en gran medida los modos forzosos de contención laboral que el estado patrimonial habilitó al servicio del capital exportador, bajo Trujillo y su sucesor, Joaquín Balaguer, presidente de la república de 1966 a 1978 y de 1986 a 1996 (Hintzen, 2016).

De esta manera, la sentencia, sus edictos y leyes asociadas no buscan la eliminación física de la presencia haitiana de la República Dominicana, ya sea a través de la limpieza étnica o la expulsión masiva. En todo caso busca la construcción de lo que Foucault (1980) llamó un nuevo «dispositivo» - estructuras de conocimiento y mecanismos institucionales, físicos y administrativos que potencian y mantienen el ejercicio del poder estatal — con el fin de suplantar los obstáculos físicos con unas barreras documentales y cibernéticas mucho más eficientes.

\section{La Sentencia 168/13}

Concretamente con el caso de Deguis, el alto tribunal dominicano confirmó que la Junta Central Electoral (JCE), la agencia que maneja el sistema del registro civil dominicano, tenía razón al negarse a emitir a Deguis una identidad oficial, sobre la base de la Resolución 12/07. El tribunal mantuvo la determinación de la Junta Central de que Deguis, nacida en República Dominicana en 1984 de padres haitianos, había sido incorrectamente registrada como dominicana al nacer, incluso nunca ostentó el derecho a la ciudadanía dominicana, por lo que ahora podía ser despojada legalmente de ella (Amnistía Internacional, 2013). El tribunal superior estipuló que su sentencia se aplicaba no sólo a Deguis, sino a todas las personas que compartían su estatus. 
A finales de 2015, el ACNUR revisó y redujo su cifra inicial de 210 mil personas despojadas de la ciudadanía dominicana como consecuencia de la Sentencia 168. Esta nueva estimación, de 133 mil 770 personas despojadas de nacionalidad, únicamente incluye la primera generación nacida en el país de ascendencia haitiana, ya que no existen cifras consistentes para las generaciones posteriores. También excluye a los individuos nacidos de parejas étnicamente mixtas, que habían sido incluidos en la estimación anterior (Acento, 2016). Estas personas, si uno de los padres es dominicano, tienen el derecho constitucional a la nacionalidad dominicana. El ACNUR declaró que esta última cifra se revisaría a medida que se publicaran cifras oficiales sobre el número de personas a las que la Ley 169 del 2014 restableció efectivamente la nacionalidad dominicana después de haber sido despojadas de ella por la sentencia.

Inicialmente, periodistas y otros observadores extranjeros reconocieron la gravedad de la Sentencia 168, pero a menudo no lograron situarla de modo correcto como parte de recientes interpretaciones oficiales de leyes y decretos burocráticos, que ya habían tenido impactos negativos en los dominicanos de ascendencia haitiana durante las décadas de 1990 y 2000 (Martínez, 2014a). Por tanto, algunos antecedentes sociales e históricos podrían ayudar a llenar este vacío histórico.

En la República Dominicana se requiere presentar copias oficiales de los documentos de identidad para llevar a cabo distintas transacciones legales: obtener un pasaporte, inscribir a un niño en la escuela o renovar la cédula nacional de identidad. A su vez, la cédula es requerida rutinariamente como verificación de identidad para otras tareas (reclamar una remesa enviada por familiares en el extranjero). La Resolución 12/07, decreto emitido en 2007 por la JCE, exige que el personal de las oficinas de registro civil locales y las oficinas centrales de la junta no expidan cédulas o copias oficiales de actas de nacimiento o cualquier otro documento de registro civil, a quien aparezca en sus archivos bajo el registro de un padre que presentara un documento de identidad distinto de la cédula oficial, en específico se trata de hijos de inmigrantes no autorizados, no obstante la posterior Circular 32/11 que pretende derogar la disposición anterior 12/07. Después, dicha revocación anunció no haber tenido efecto porque fue emitida por la Dirección Nacional del registro civil y no por la Plenaria de la JCE (Movimiento por un Registro Civil Libre de Discriminación, 2011). 
Durante las décadas anteriores a la de 1990, un número desconocido de personas de ascendencia haitiana nacidas en República Dominicana obtuvieron la ciudadanía oficial cuando los padres haitianos registraron el nacimiento de sus hijos usando tarjetas de identificación temporales para los trabajadores estacionales de la caña de azúcar (Garcia, 2006). Aunque el racismo antinegro ha dificultado el conseguir la ciudadanía dominicana a lo largo de varias décadas fue facilitada por funcionarios del registro civil a nivel local. Estos funcionarios de nivel local aprobaron la emisión de decenas de miles de certificados de nacimiento válidos a los hijos dominicanos de padres haitianos, a menudo sin solicitar ninguna prueba de identidad que no fueran las cédulas de identidad temporales (carnets temporeros o fichas) expedidas a los trabajadores temporeros por las empresas azucareras a su llegada de Haití. Rafael Trujillo, gobernante dictatorial del país de 1930 a 1961, siempre favoreció la emisión de la cédula a todos, como herramienta de control político.

Posteriormente, la política electoral y la creación de pequeños bolsillos de electores y clientes políticos agradecidos en las plantaciones azucareras con seguridad pudieron haberse involucrado en ello. En los 1980, las perspectivas del mercado del azúcar pasaron de optimistas a deprimidas y la permisividad oficial fue reemplazada por una restricción creciente. En 1990 se descubrió que a los hijos de ascendencia haitiana de origen dominicano se les negaban certificados de nacimiento bajo el pretexto de que la Constitución dominicana eximía a los hijos de las personas «en tránsito» del derecho del jus soli a la nacionalidad dominicana (Cedeño, 1992:139; Lawyers Committee for Human Rights, 1991:13-14). El Centro Cultural Dominico-Haitiano (CCDH), en 1997, encontró una clara indicación de que a los jóvenes se les impedía adquirir sus cédulas: se estima que un 80 por ciento de los dominico-haitianos de más de treinta años poseían una cédula, pero sólo el 30 por ciento de los menores de treinta años tenían este documento (CCDH, 1997:16).

En 2004, la Sección VII, artículo 10 de la Ley General de Migración (República Dominicana, 2004:22) declaró oficialmente que todo aquel que no fuera residente legal estaría, a efectos de la ley, «en tránsito» y, por lo tanto, los nacidos dominicanos con ascendencia haitiana quedaban excluidos del derecho a la ciudadanía de nacimiento (Baluarte, 2006:28). Desde hace algunos años se les niegan de forma provisional copias de sus documentos oficiales cuando los solicitan en las oficinas del registro civil. Mientras esperan la investigación de las historias de inmigración de sus padres, las personas afectadas viven en un limbo legal y 
su ciudadanía es revocada. Para el derecho internacional se trata de una forma de apatridia (van Waas, 2007:445-450): la relación de pertenencia que los afectados han tenido desde su nacimiento con el estado de su nacimiento queda suspendida y quizá anulada, sin tomar en cuenta si en la práctica es posible alcanzar la nacionalidad haitiana de sus antepasados inmigrantes. Miles han sido arrojados a una ciudadanía en limbo cuando al intentar renovar sus cédulas u obtener documentos oficiales de réplica para la matrícula universitaria o viajes al extranjero, la inspección de sus certificados de nacimiento constata que podrían ser descendientes de un residente irregular (Garcia, 2006:21). Ahora el gobierno argumenta que la exclusión «en tránsito» de los hijos de inmigrantes indocumentados del jus soli ha sido su política oficial desde siempre, si bien esa política careció de contenido jurídico público hasta la Resolución 12/07 de 2007; en ese momento, la JCE anunció que podría suspender la ciudadanía de cualquier solicitante en espera de una investigación forense de la situación migratoria de sus padres al nacer.

A pesar de que la decisión del 23 de septiembre iba más allá de confirmar la validez de la Resolución 12/07, la sentencia no contemplaba de forma explícita las deportaciones masivas, ni mucho menos las ordenaba. En cambio, la corte exigió grandes tareas que serían realizadas en el plazo de un año por otros tres sectores del gobierno, el Ministerio del Interior y la Policía Nacional con sus autoridades de Migración, la JCE y el Congreso Dominicano. En principio, el tribunal demandó a las autoridades de policía y migración que elaboraran una lista de los individuos que vivían en el país y que no tenían un permiso de residencia legal. En segundo lugar, encomendó a la JCE que recopilase una lista de «extranjeros» (es decir, los hijos nacidos en la República Dominica de padres extranjeros sin residencia legal) cuyos certificados de nacimiento hubieran sido «irregularmente» inscritos en el registro civil de la nación desde 1929 (el año en que la excepción «en tránsito» de la constitución a la elegibilidad para la ciudadanía jus soli se hizo efectiva). Un indicador clave de la inscripción irregular se relaciona con el hecho de si el nacimiento del niño fue registrado por los padres que llevaban una cédula legalmente expedida o algún otro tipo de documento de identidad, como un carnet temporero. La lista de JCE debería extenderse para incluir asimismo a aquellos que han sido fraudulentamente "cedulizados», al ser inscritos como hijo(s) de un dominicano que no era en realidad su madre o padre, última estrategia con frecuencia utilizada para obtener la cédula por haitianos y dominicanos descendientes de haitianos. La sentencia ordenó que dichas 
personas fueran despojadas de la ciudadanía dominicana si su nacimiento se remontaba a inmigrantes sin residencia legal permanente. En tercer y último lugar, el Tribunal Constitucional pidió al Congreso que elaborara un Plan Nacional de Regularización de Extranjeros Residentes no Autorizados, tal como ya se solicitaba en la Ley General de Migración de 2004. Ese plan tendría como objetivo proporcionar un camino a la residencia legal a los que carecieran de estatus legal y a los de origen dominicano que debían ser despojadas de su ciudadanía tras el análisis forense de sus certificados de nacimiento por parte de la JCE. Estas tres piezas fueron pensadas para encajar de manera unificada en un esquema legal, forense y administrativo.

\section{Respuesta del gobierno dominicano}

En el frente administrativo, un primer acontecimiento se suscitó en noviembre de 2013, cuando el presidente dominicano, Danilo Medina, decretó el Plan Nacional de Regularización de Extranjeros Residentes no Autorizados (PNRE, República Dominicana, Oficina de la Presidencia, 2013). El plan entró en vigor a principios de junio de 2014, con la eventual apertura de instalaciones especiales de registro en las oficinas del registro civil en 24 de las 32 provincias del país (OBMICA, 2015:4). Antes de que tuviera efecto era previsible incluso que muchos inmigrantes haitianos indocumentados no podrían reunir los tipos de documentos que solicitaban para probar su elegibilidad. Luego de la sentencia, Martínez (2014b) previó que aquellos que tuvieran empleo formal y propiedad propia tendrían un acceso más fácil a los documentos que atestiguaran el tiempo que habían vivido en la República Dominicana, el lugar donde estaban empleados y los vínculos familiares que tenían. Cabe destacar que éstos poseían una clara ventaja sobre aquellos que carecían de documentos que demostraran que merecían permanecer como residentes legales. Las cifras oficiales de la Oficina Nacional de Estadística (ONE, 2013), en la primera encuesta nacional de los inmigrantes en 2012 en la República Dominicana, anunció que 458 mil 233 personas no contaban con un estatus migratorio positivo.

Adicionalmente, en octubre de 2016 se notificó que 249 mil 830 personas se habían inscrito en el PNRE (34 por ciento mujeres y 66 por ciento hombres) (República Dominicana, Ministerio de Interior y Policía, 2016). Es importante precisar que un porcentaje muy pequeño de los que se inscribieron (menos de $10 \mathrm{mil}$ 
personas), completaron la documentación requerida y se les concedió la residencia permanente, en realidad ese había sido el objetivo neto del programa. Una ventaja de este último estatus es que tal residencia legal es un requisito previo para que los extranjeros registren a sus hijos nacidos en la República Dominicana como dominicanos. Los decepcionantes resultados se explicarían de dos modos posibles, que la barra de documentación se estableció demasiado alta para que la mayoría de los inmigrantes irregulares fueran descalificados, o bien que el plazo para la regularización era muy corto, o ambos.

Un desafío particular para los indocumentados fue conseguir los papeles de identidad haitianos de los que muchos carecían. En apoyo del PNRE, las autoridades haitianas iniciaron un Programa de Identificación y Documentación de Inmigrantes Haitianos (PIDIH). A pesar del decreto de hacer operacional este programa en enero de 2014 (République d'Haïti, 2014), el gobierno sólo logró establecer cinco centros, uno de ellos en Barahona, en abril de 2015, días antes de que terminara el periodo de inscripción del PNRE. Alrededor de 45 mil personas lograron registrarse en la PIDIH, pero sólo el 5 por ciento recibieron sus pasaportes antes del vencimiento del proceso de inscripción para el Plan de Regularización, el 17 de junio de 2015.

Aquellos que se registraron en el PNRE pero no obtuvieron la residencia permanente han sido elegibles para estadías temporales de dos años; dichas residencias temporales llegarán a la fecha de su renovación, desde mediados de 2017 en adelante. La incertidumbre continúa en cuanto a los derechos que los migrantes temporalmente regularizados pueden tener a los servicios y subsidios gubernamentales, incluida la seguridad social. Aunque ciertas disposiciones complementarias se están poniendo en práctica, necesitarán intensificarse a fin de que los residentes legales condicionales y permanentes obtengan beneficios por encima de la suspensión de la deportación.

El Congreso dominicano prosiguió en mayo de 2014 con la referida Ley 169, estableció un protocolo especial para afirmar la ciudadanía dominicana de aquellos a quienes se les habían otorgado documentos de identidad oficiales previo a 2007 sobre la base del registro de su nacimiento en suelo dominicano (República Dominicana, Congreso Nacional, 2014). En el caso de los nacidos en República Dominicana de ascendencia extranjera cuyos nombres no aparecían en el registro civil, la ley también proporcionó un camino a la residencia legal y luego a la ciudadanía dos años después. La Ley 169 se caracterizó por ser una ley liberal, aun cuando indicó un principio básico de exclusión, acordado en una enmienda 
de 2010 a la Constitución Dominicana, que a los hijos dominicanos de inmigrantes no autorizados se les negaría la ciudadanía. En lo que respecta al derecho de los descendientes de haitianos a la nacionalidad del jus soli — cuestión tratada por la Ley 169 - los observadores de la derecha xenófoba y de la izquierda liberal habían entendido que la Sentencia 168 era clara al confirmar que la ciudadanía sería revocada de manera retroactiva a los descendientes de inmigrantes no autorizados. La Ley 169 asentaba medidas contrarias a ese objetivo, en el preámbulo argumentaba que ni siquiera los registrados de modo indebido eran culpables si otros cometieron el error de registrarlos al nacer como dominicanos. Asimismo, se mencionaba el interés del Estado en proteger una gama de derechos individuales, incluyendo la igualdad, el desarrollo humano y la nacionalidad, como fundamento para establecer procedimientos con la intención de otorgar la nacionalidad dominicana a los nacidos en la República Dominicana. Esa concesión se distinguió como excepcional, con una fecha límite en 2007 vinculada a la elegibilidad, se fijaron fronteras que permitían a los autores de la ley conducirse con al menos tres requerimientos políticos: permanecer fiel a lo estipulado en la Sentencia 168, mitigar el enorme potencial de la sentencia de promover la disrupción social y el conflicto legal, y trazar una línea luminosa en el tiempo pasado mediante la cual no más hijos de haitianos sin derecho legal de residencia serían aceptados como nacionales dominicanos.

Como se ha comentado, la Ley 169 clasificó a las personas nacidas en el país de padres extranjeros residentes irregulares no como dominicanos sino como extranjeros. La ley dividió a estas personas en dos grupos. El grupo A comprende a los que poseían documentos oficiales de identidad dominicanos. Tal nacionalidad sería reconocida efectivamente porque el Estado asumió su error administrativo al efectuar el registro sin haber nacido en territorio dominicano. El grupo $B$ contiene a aquellos que carecían de cualquier tipo de documento de identidad. A ellos la ley los clasificó como extranjeros en su propio país de nacimiento, además les obligó a seguir un proceso de naturalización a fin de conseguir la ciudadanía dominicana, aun cuando todo el tiempo la habían asumido como suya por derecho.

De inmediato, la ley sobrecargó a los proponentes de los derechos liberales de la sociedad civil dominicana con un dilema: cooperar, ayudando a los dominicanos que estaban en riesgo de convertirse en apátridas para presentar demandas legales sólidas al Estado, o mantener su superioridad moral rechazando todo el proceso como descaradamente antihaitiano. Las organizaciones de la sociedad 
civil vieron una valiosa oportunidad dentro de la Ley 169 para reducir la vulnerabilidad de las personas del grupo B, que no tenían documentos de identidad y por tanto se encontraban en riesgo de apatridia. Los activistas consideraron que el lado positivo de la ley fue que dio visibilidad a la situación de esas decenas de miles de descendientes de haitianos nacidos en República Dominicana cuyo nacimiento nunca había sido registrado. En ambos grupos los resultados en los hechos han sido mixtos.

En junio de 2015, la JCE publicó los nombres de alrededor de 55 mil personas del grupo A, a quienes en teoría les restauraron sus documentos dominicanos. Las organizaciones de la sociedad civil meses después informaron que muy pocos en la lista habían recibido sus cédulas (Acento, 2015). Dicha denuncia parece haber precipitado una nueva disposición administrativa 24/15 de noviembre de 2015 (El Caribe, 2015), revocaba la Resolución 12/07. Tanto la presión internacional como la local conminó para que al grupo A se le regresaran de manera más sistemática los documentos. El estatus de los defensores de derechos liberales en la sociedad civil dominicana, como interlocutores válidos con el Estado, se ha consolidado, al menos mientras los representantes de instituciones internacionales como Human Rights Watch o la Comisión Interamericana de Derechos Humanos permanezcan de su lado (Diario Libre, 2016). No obstante, al asumir sus funciones en noviembre de 2016, la nueva Junta Central Electoral observó que apenas 13 mil personas del grupo A habían recuperado algunos de sus documentos.

El destino del grupo B es todavía más turbio. En teoría, las personas no registradas de ascendencia extranjera estaban obligadas a presentar sólo uno de los cuatro tipos de los documentos siguientes: a) un certificado de nacido vivo emitido por el hospital, b) una declaración jurada notarial con siete testigos, c) una declaración jurada de la comadrona, d) una declaración jurada notarial de parientes dominicanos. Con todo y eso, los solicitantes aseguran haber sido rechazados luego de que se les solicitó más de uno de los documentos o se añadió un documento a la lista, por lo común un documento de identidad de la madre. Este último requisito refuerza el sesgo de género en la Ley General de Migración de 2004, al exigir que las madres extranjeras registren a sus hijos nacidos en suelo dominicano a través de los "papeles rosados», diferenciándolos de las madres nativas y dejando de lado los derechos del padre en el proceso (Petrozziello et al., 2014). Los documentos de identidad de los padres de los solicitantes se incluyeron como requisito en las instrucciones difundidas por el Ministerio del Interior y la 
Policía el 9 de septiembre de 2015 para solicitar la inscripción en el Libro de Extranjería, como registro especial de los nacidos vivos de residentes extranjeros, creados por la Ley General de Migración. Las actas de nacimiento de las madres sólo serían aceptadas si se autentificaban legalmente y se traducían al español. En resumen, se requería una documentación adicional costosa, a pesar de que las instrucciones del ministerio del 9 de septiembre fueron retiradas después (Riveros et al., 2015:151-153).

Cualquiera que fuera a la razón, sólo unas 8 mil 755 personas del grupo B al finalizar el periodo de inscripción, el 1 de febrero de 2015, aprovecharon la oportunidad de inscribirse para la naturalización conforme a la Ley 169. Las autoridades informaron que 2 mil 464 personas habían recibido residencia permanente a principios de 2016 (Faxas, 2016). Así, las perspectivas de naturalización definitiva entre el grupo B como dominicanos siguen siendo inciertas.

\section{Exclusionismo anti-haitiano: la nueva generación}

Los tres años siguientes a la sentencia vieron la indignación inicial dar paso primero a un optimismo cauteloso y luego a la decepción. El gobierno de Santo Domingo parecía ceder a la defensa local y de ultramar al mostrar una voluntad de regularizar los estatus de los indocumentados y de personas apátridas por la anulación de su ciudadanía. Sin embargo, como ya se demostró, ahora que los periodos de registro han expirado, los tres procesos han dado resultados mixtos.

Con probabilidad, el futuro brindará razones aún más alarmantes. Una medida que la Ley 169 no modificó y que casi no se discutió en los debates públicos sobre el despojo de la nacionalidad, es la que excluye "lícitamente» de la ciudadanía a los hijos dominicanos de inmigrantes indocumentados nacidos después de 2007. Quizá este grupo de dominicanos de nacimiento sin ciudadanía crezca gradualmente a proporciones de crisis, ya que el PNRE no alcanza a contabilizarlos a todos, el número continúa ascendiendo. En perspectiva, lo que se contempla tácitamente en el corpus de la juridización reaccionaria — sobresalen la Ley General de Migración, la Resolución 12/07, la Constitución de 2010 y la Sentencia 168 - no es la expulsión territorial de haitianos y descendientes de haitianos, sino su incorporación como personas de segunda clase en la economía política dominicana. A los descendientes de haitianos se les excluirá no necesariamente 
del territorio dominicano, sino de los beneficios más importantes de la ciudadanía dominicana. En ese sentido, lo más escalofriante no es la expectativa de que los «excesos» del estilo antiguo continuen (aunque de esto queda poca duda), sino la adición a esos abusos de un nuevo estilo de exclusión legal y burocratizada. La distinción entre el viejo exclusionismo y un nuevo exclusionismo «biopolítico» es fundamental referente a lo que se pretende plantear y demanda una mayor explicación.

El exclusionismo antiguo consiste en abusos que han sido conocidos por los defensores de los derechos durante décadas y que han sido descritos de modo extenso por Human Rights Watch (2015, también Boalt Hall School of Law, 2002; Granne, 2001). Cualquiera que parezca o suene "haitiano» a la policía, los militares o los funcionarios de migración, es vulnerable a golpizas, acoso e incluso expatriación sin el debido proceso. Las expulsiones extrajudiciales han sido tema de particular preocupación de los derechos humanos internacionales y han ocurrido a un ritmo acelerado desde que el primer gobierno de Leonel Fernández PLD tomó el poder en 1996. Decenas de miles de haitianos indocumentados han sido repatriados cada año a través de procedimientos que ignoran estándares mínimos del proceso adecuado. En contravención de la disposición de la ley dominicana de los derechos del justo proceso a los extranjeros en los procedimientos de deportación, las expulsiones a Haití se realizan en cuestión de horas o días después de la detención, sin autorización judicial ni una comparecencia ante un tribunal. Probablemente la derecha xenófoba incremente la presión para expandir aún más las expulsiones, en especial si los resultados alcanzados a través del PNRE y la Ley 169 continúan fallando en lograr lo que el Tribunal Constitucional ha ordenado. En enero de 2016, Jonathan Katz (2016), reportero del New York Times, reveló que miles de inmigrantes y dominicanos del grupo B se habían agrupado en un asentamiento provisional de desplazados forzosos, Parc Cadeau, justo al otro lado de la frontera haitiana desde la ciudad suroccidental dominicana de Pedernales. Según Katz, varias de estas personas desplazadas habían sido hostigadas por nacionalistas dominicanos para repatriarse o expatriarse a Haití al temer por su seguridad. Tal parece que el uso de las vejaciones al estilo antiguo mediante amenazas y fuerza bruta sigue vigente.

Es todavía peor el efecto del fallo de la corte sobre las generaciones futuras de personas dominicanas de ascendencia haitiana. Serán ellos los que se enfrentarán al amargo destino de no tener acceso ni a la ciudadanía dominicana ni a las medidas de regularización promulgadas por el Presidente Medina y el 
Congreso Dominicano. En la comprensible urgencia que se ha otorgado a la difícil situación de los dominicanos que se convirtieron en personas apátridas a consecuencia de la anulación de la nacionalidad, se ha prestado poca atención al futuro de los niños nacidos de padres que no residen legalmente en el país desde 2007. Dentro de la nueva forma de exclusión «normativa» y burocratizada, apoyada y esbozada por la Sentencia 168, el estado civil deteriorado de los padres inmigrantes indocumentados, ahora será heredado a perpetuidad por sus hijos nacidos en territorio dominicano y por sus descendientes. La exclusión de la ciudadanía jus soli perseguirá a los niños nacidos después de 2007, incluso a aquellos que pudieran sentir un alivio de su pesadilla al ser retroactivamente despojados de la ciudadanía. Las oportunidades de los futuros descendientes haitianos de escapar de la pobreza estarán amuralladas, no por cercas de alambre de púas y guardias de armas (Martínez, 2012), sino de forma invisible por documentos de identidad, bases de datos computarizadas y guardianes institucionales. Más probable que la deportación en masa y casi tan aterrador es la creación de una nueva y cada vez mayor clase de ciudadanos con discapacidad civil, personas que en términos culturales son dominicanas pero que ostentarán ciudadanía extranjera (haitiana) o no gozarán de ciudadanía en absoluto. Los primeros serán funcionalmente apátridas si no tienen la intención de vivir en Haití y los últimos serán apátridas de manera formal y aunque parezca irónico incapaces de salir del territorio dominicano a menos que sean expulsados. Los miembros de esta minoría interna permanentemente desnacionalizada tendrán, en el mejor de los casos, oportunidades desiguales para obtener títulos universitarios y visas para viajar al extranjero, ejercer derechos de propiedad legales, los canales a través de los cuales los dominicanos por millones han buscado movilidad social ascendente. Así, las reformas de nacionalidad que los nacionalistas dominicanos defienden como un medio para frenar el crecimiento de la presencia haitiana, con seguridad tendrán el efecto contrario, de hacer más difícil que los descendientes de haitianos abandonen la República Dominicana.

\section{¿Un giro biopolítico?}

La lógica de la Sentencia 168 no es la limpieza étnica, ni la esclavitud moderna, ni siquiera la aplicación obligatoria de la ley de inmigración, sino una legalización del no-otorgamiento de la ciudadanía y los derechos. El bloqueo al acceso de los descendientes de haitianos a las escalas de adelanto socioeconómico, 
como la educación y los viajes al extranjero, obstaculizará su capacidad para realizar su máximo potencial humano y, por ende, los confinará, sin guardias, puertas cerradas o cercas, a vidas de subordinación, explotación injusta y pobreza. Mediante las nuevas tecnologías legales y de la información, los descendientes de haitianos no quedarán físicamente detrás de las vallas de alambre de púas, sino imposibilitados de acumular capital humano o credenciales económicas como títulos universitarios y visados de viajes internacionales, necesarios para conseguir comodidad y respeto. Esta restricción civil de las capacidades de los descendientes de haitianos es lo nuevo y posiblemente más peligroso de la Sentencia 168. Juridicalizar una antigua agenda antihaitiana por medio de normas legales y administración de datos burocráticos, más que cubrir viejas formas de maltrato bajo una capa de legitimidad jurídica, también implica una nueva forma de control, más insidiosa y más difícil de evadir de lo que fue el antiguo exclusionismo.

La novedad de este giro es subestimada y merece un escrutinio. Evidencia de lo poco que se entiende la situación actual en el extranjero, incluso entre personas bien informadas sobre noticias latinoamericanas; un colega en literatura latinoamericana nos comentaba que los recientes acontecimientos en la República Dominicana eran «como un regreso a 1937» (año de la masacre de Trujillo a decenas de miles de personas de ascendencia haitiana en áreas de la frontera con Haití). Es cierto que el genocidio es más una técnica del estado moderno que un antiguo atavismo (Foucault 1978:137) y, al igual que los asesinatos masivos de 1937, la Resolución 12/07 y la Sentencia 168 son actos a través de los cuales los líderes del estado promueven la consolidación nacional mediante la exclusión del otro, nacional y racialmente definido. Sin embargo, resulta determinante que la Resolución 12/07 sea, como dijo el periodista dominicano Juan Bolívar Díaz (2011), un "genocidio civil» y no un genocidio armado. Mientras que la aspiración nacionalista es todavía hoy cimentar una frontera etnoracial con Haití, los medios previstos por la Sentencia no son amenazas, golpizas, asesinatos y expulsiones sino tecnologías burocráticas de registro personal y manejo de datos. En esencia, es fundamental que las armas favorecidas de exclusión biopolítica no sean escopetas y alambradas sino computadoras y documentos del Registro Civil.

No somos los primeros en caracterizar estos recientes desarrollos en el exclusionismo antihaitiano como un giro biopolítico (Lippmann y Marcelino, 2014:167-168), al marcar una progresión lenta pero discernible del «derecho a 
tomar vida o dejar vivir» Trujillista y hacia «un poder para fomentar la vida o prohibirla hasta el punto de la muerte» (Foucault, 1978:138). Foucault (1978:Ch. 5), en su tan citado capítulo, "Derecho de muerte y poder sobre la vida», acuñó el término «biopolítica», cuyo significado es la creación de nuevas formas de conocimiento sobre la sociedad y la población, y luego cómo ese conocimiento se usa en el gobierno. La biopolítica es una cibernética social que funciona clasificando subpoblaciones, en niveles que van desde el individuo a la población en su conjunto, ya sea por medio de diversas cuantificaciones de hechos o mediante la cartografía de la desviación humana de las normas, o ambos. Existen diversas acciones clave del gobierno en torno a la biopolítica: encuestas, registros, asignaciones y sistemas de recuperación e integración de información en registros civiles, escuelas, policía y ejército, o más generalmente, «las previsiones, las estimaciones estadísticas y las medidas generales (...) mecanismos de seguridad (...) instalados alrededor del elemento aleatorio inherente a una población de seres vivos para optimizar un estado de vida» (Foucault, 2003:246).

La línea entre «hacer vivir» $y$ «dejar morir» se dibuja cuando el Estado otorga a un ciudadano condiciones de prosperidad humana o retiene derechos a quienes caen en el lado equivocado de la norma dentro del esquema clasificatorio del estado de regularización. El estado biopolítico mejora las condiciones de vida de un segmento de la población mientras que el otro es desechable debido a la negligencia. En un extremo, durante los estados de excepción, el descuido puede agravar la persecución y reducir ciertos segmentos enteros de la ciudadanía a la mera supervivencia biológica, sin derechos o incluso su conversión en objetivos de eliminación, como ocurrió con judíos, gitanos y otros en los campos de concentración nazis. «Vida desnuda» es el nombre que el filósofo Giorgio Agamben (1998) otorga a esta condición de ser biológicamente vivo pero sin derechos. Los teóricos políticos John Lechte y Saul Newman (2013:13) afirman de manera categórica: «Los refugiados, solicitantes de asilo y migrantes «ilegales», debido a su falta de estatus legal y político, se reducen precisamente a una «vida desnuda»». En vez de emplear esos artificios retóricos, creemos que es más exacto decir que los inmigrantes haitianos y los dominicanos de ascendencia haitiana están siendo relegados a los peldaños inferiores de un sistema de variegated citizenship, lo que los vuelve más vulnerables al daño, a muertes tempranas y prevenibles, que Foucault lo denomina ser «dejado a morir».

La etnóloga Aihwa Ong (1999:217) percibe el funcionamiento de sistemas de variegated citizenship en diversos estados de acogida de inmigrantes, «en los cuales 
las poblaciones sometidas a diferentes regímenes de valor disfrutan diferentes tipos de derechos, disciplina, cuidado y seguridad». Bajo esquemas de variegated citizenship "algunos sujetos están investidos de derechos y recursos, otros son descuidados de manera directa» (127). Mientras que los resultados varían, la privación resultante en extremo puede ser mortal. Proyectada en la geopolítica, principalmente a través del control migratorio, la biopolítica perpetúa «la distribución del mundo globalizado en 'zonas de vida) (donde los ciudadanos están protegidos por una serie de técnicas de salud y seguridad) y 'zonas de muerte donde existen «vidas sin valor) (que están expuestas a enfermedades, accidentes y guerras, y son dejadas a morir)» (Campbell y Sitze 2013:19). Todavía más, el asentamiento de desplazamiento forzado de Parc Cadeau puede incluirse entre las «zonas de muerte» del mundo.

Lo que también marca ese momento como biopolítico es que trae a consideración distintas cuestiones de lo que significa para el gobierno dominicano ser un Estado y gobernar, asuntos que Foucault llamó gouvernemantalité (gubernamentalidad). Él mismo en sus conferencias sobre el nacimiento de la biopolítica, abordó la gubernamentalidad como un aparato de poder administrativo «que tiene como objetivo a la población, a la economía política como su principal forma de conocimiento y a los aparatos de seguridad como su instrumento técnico esencial» (Foucault, 2007:108-09). Silenciosamente cirniéndose sobre la Sentencia 168 se encuentra la distancia entre el Estado dominicano tal cual es y el estado que la sentencia presenta como «el que debe ser construido» (Foucault, 2008:3-4). Cuando se ordenó la compilación de listas de todos los inmigrantes sin estatus legal del país y de todos los individuos irregularmente cedulizados en menos de un año, el Tribunal Constitucional imaginó una burocracia estatal de muy alto funcionamiento. La brecha entre este estado imaginado y el actual estado dominicano conduce a la incógnita de si el fallo tenía grandes espectativas o estaba en realidad diseñado para fracasar. De cualquier manera, una agenda velada de la sentencia fue la de mejorar la inteligencia, la burocracia, la policía y las tecnologías legales para llevar a cabo sus fines; para que el Estado dominicano, en suma, pudiera gobernar más como debería.

En consecuencia, la JCE, cuya función principal fue en un principio garantizar el proceso electoral, está apostando ahora, con agresividad, a la pretensión de ser un garante biométrico de la seguridad nacional. La tecnología se concibe como el próximo baluarte contra la temida haitianización: procesos en curso de digitalización de documentos básicos del registro civil, eliminación de individuos 
"cedulizados» de manera irregular e introducción de una cédula nueva, "segura», con los datos biométricos únicos de su titular, todos son proyectos de alto perfil, que dan esperanzas a los nacionalistas dominicanos de que un muro biopolítico virtual pronto podrá lograr una exclusión más absoluta de lo que jamás podría haber logrado una policía de gran alcance. Resta observar si el Estado dominicano estaría a la altura de esa aspiración. Lo que no se puede negar es que una poderosa coalición de actores políticos apoya el proyecto de la JCE con el objeto de que se convierta en el constructor tecnológico tácitamente imaginado por la sentencia. Y aquí, una vez más, la conformidad se coloca por encima de la desviación de los estándares globales de gobierno: medidas de seguridad exigidas por los Estados Unidos y la Unión Europea y subcontratadas de forma contractual por empresas multinacionales para el desarrollo son adoptadas pero luego transformadas con el propósito de alcanzar metas exclusionistas de carácter étnico.

Cabe mencionar que lo que para nosotros marca las tendencias recientes en el antihaitianismo como «biopolítico», es que se preveé un nivel de control estatal hasta ahora nunca imaginado, además dicho control se ejercerá cada vez menos íntimamente, «de primera mano», por el ojo del policía y por su bastón, y cada vez más institucionalmente, "por control remoto», a través de documentos y mecanismos de gestión de datos. Ello no representa una disminución de la ley a favor de la norma, sino una redefinición de la ley con la intención de trabajar menos como un instrumento para el confinamiento de los individuos y más como un instrumento para la clasificación y manejo de las poblaciones como conjuntos diferenciados. A fin de tomar el lugar de la fuerza directa, interpersonal y la vigilancia constante, la Sentencia 168 anticipa una dotación selectiva, legalmente codificada y administrada de modo burocrático, a distintos niveles de la población. Entre las líneas de la sentencia existe un muro virtual que permitirá la entrada selectiva a los haitianos, según sea necesario; no obstante, su estancia será precaria y nunca consentirá que la población de ascendencia haitiana pertenezca plenamente a la sociedad dominicana.

Este objetivo concuerda con un tercer y frecuente comentado aspecto de la biopolítica, que Foucault enfatizó en su obra posterior sobre la gubernamentalidad; se refiere a los efectos de la biopolítica respecto de la subjetividad de cada persona como individuo. La biopolítica forja cada sujeto en un autónomo «empresario de sí mismo, siendo para sí su propio capital, siendo para sí su propio productor, siendo para sí mismo la fuente de sus ganancias» (2008:226). Esto corresponde al ideal neoliberal del buen ciudadano como uno para quien el 
comando estatal es superfluo, porque responde de forma racional a los incentivos para seguir los canales establecidos por el poder. El buen ciudadano se responsabiliza de sí mismo sin intervención ni castigo (Hamann, 2009).

Aquellos que no pueden ejercer una responsabilidad efectiva (por ejemplo, reuniendo los documentos necesarios para demostrar que merecen residencia legal permanente), de acuerdo con la ideología neoliberal, no tendrán a quien culpar por «perder» más que a sí mismos: «El neoliberalismo gobierna al metaforizar el mercado como un juego, al metaforizar al Estado como su árbitro y al metaforizar a individuos y poblaciones como jugadores para quienes todas las opciones son en principio posibles - con la única excepción de la opción de no jugar el juego» (Campbell y Sitze, 2013:20). En ese juego, la responsabilidad se echa sobre cada individuo para demostrar su merecimiento de la protección estatal, los deberes y los derechos. Así, a medida que los procesos de regularización y naturalización se desarrollaron en la República Dominicana en 2014, 2015 y 2016, se evidenció que quienes podían producir un expediente con documentos de su escolaridad e historias de empleo en el sector formal, tenían una clara ventaja sobre aquellos sin un «papel legal» al aprobársele su nuevo estatuto jurídico, sin que se tuvieran en cuenta las diferencias en la capacidad de los individuos.

La nueva marca de exclusionismo antihaitiano ha estado tomando forma en la República Dominicana desde la aprobación de la Ley General de Migración de 2004. Esa ley equiparaba a los residentes no autorizados con personas «en tránsito», sin importar cuánto tiempo tales residentes extranjeros habían residido en realidad en el país. La torpe lógica mediante la cual un residente de décadas, se podría decir «en tránsito», hizo a los niños nacidos en la República Dominicana excluibles de la ciudadanía dominicana. Desde ese incómodo comienzo, una serie de revisiones de la ley ha buscado controlar a las personas de ascendencia haitiana cada vez menos mediante la fuerza arbitraria, y cada vez más a través de leyes codificadas y procedimientos burocráticos.

En el sueño del xenófobo, cada descendiente haitiano en la República Dominicana nacido después de 2007 llevará un documento oficial que lo verifique como sujeto a quien no le corresponden ciertos derechos. El objetivo no es la exclusión sino la inclusión con una restricción de capacidades. Y aun cuando se persigue un objetivo antiliberal, de crear una subclase proletaria permanente, una apariencia liberal de la normatividad legal prevalece la nueva exclusión. Con la aprobación de la Ley General de Migración de 2004, seguida por la Resolución 
12/07 y luego la adopción de la Constitución Dominicana en 2010 para permitir la exclusión de niños de inmigrantes no autorizados de los derechos de ciudadanía jus soli, por las decisiones de los tribunales superiores dominicanos en 2005, 2011 y 2013, la base del exclusionismo antihaitiano atraviesa de la costumbre y la fuerza grosera, a la ley y la administración pública. Frente a ese telón de fondo histórico, la Sentencia 168 parece ser nada menos que el clímax de una tendencia de años.

\section{Un nuevo antihaitianismo para una nueva economía política dominicana}

Si este giro es o no «biopolítico» no es tan importante a nuestro juicio como lo es mantener un diálogo acerca de lo que es nuevo aquí. Consideramos que lo que hoy ocurre en la República Dominicana no es ni un regreso a 1937, ni una toma de posición defensiva de una elite prehistórica detrás de muros de piedra metafóricos. La novedad de la situación actual es irónicamente oscurecida cuando medios audiovisuales anticuados de justicia social (como el documental The Price of Sugar de 2007 y las constantemente reproducidas imágenes del pogromo antihaitiano en Pueblo Nuevo, Mao, de 2005) son desplegados ahora por activistas de derechos liberales con la finalidad de hacer las líneas del conflicto dramáticamente visibles. Ni las llamas y el clangor del pogromo ni las imágenes de los haitianos que se mantienen a punta de pistola detrás de alambradas de alambre de púas representan lo que la crisis es en el presente. En los últimos años, los inmigrantes haitianos y los dominicanos de ascendencia haitiana se mueven cada vez más libremente por el territorio dominicano, pero cada vez son menos capaces de escapar de los viciosos y cíclicos efectos de ser indocumentados, no calificados y sin credenciales. Las salidas de la pobreza están siendo burocráticamente selladas, incluso cuando las circunstancias económicas dejan a la mayoría de los descendientes de haitianos con la única opción de huir de un sector agroexportador senescente.

Algunos podrían preguntar qué diferencia hace si la contención social y económica de los descendientes de haitianos se hace de manera legal y burocrática o arbitraria y por la fuerza. ¿̇No es el resultado final que los descendientes de haitianos estén confinados a las labores relacionadas con el trabajo doméstico, el trabajo agrícola, la excavación de cimientos y el transporte de baldes de cemento en los sitios de construcción? 
Una de las razones por las que importa es que el nuevo modo de exclusión concuerda mejor que el viejo con las demandas más variadas y flexibles de incorporación del trabajo haitiano. El reemplazo de las vallas físicas por barreras socioeconómicas se ajusta a la perfección con una nueva agenda política económica: mantener a los inmigrantes haitianos y los descendientes de haitianos necesitados y vulnerables, pero libres de moverse hacia donde su trabajo puede estar en demanda. Según el filósofo Paolo Virno, el control sobre la fuerza de trabajo (la capacidad de trabajo del individuo que Marx dijo se convirtió en una mercancía comercializable bajo el capitalismo) puede explicar por qué no es coincidencia que tanto la reforma de la migración/nacionalidad como una agenda neoliberal emergen simultáneamente en el post-1990 en la República Dominicana: «La vida está en el centro de la política cuando el premio que se gana es... poder de trabajo. Por esta razón, y sólo por esta razón, es legítimo hablar de «bio-política» (Virno, 2004:83). Ello puede ser una manera abstracta de hablar de los matrimonios de la xenofobia con el oportunismo económico que se suscitan cuando los comentaristas de derecha denuncian la inmigración fuera de control, para llamar más inmigrantes al momento siguiente para sus trabajos de jardinería y construcción. En opinión de la politóloga y comentarista Rosario Espinal (2015), «la mayoría de los haitianos en territorio dominicano no se irá, ni serán repatriados ni legalizados, porque el Estado dominicano y muchos empresarios necesitan esa mano de obra barata para explotarla».

\section{Conclusión}

Entre los nuevos y más destructivos efectos del legalizado exclusionismo antihaitiano actual es que mella más en la sociedad que el antiguo exclusionismo informal. Las primeras víctimas de la Resolución 12/07 han sido en su mayoría jóvenes adultos que habían estado seguros en su ciudadanía dominicana, siendo portadores de auténticas cédulas oficiales. Ahora, no sólo los oprimidos y los sin papeles, sino los aspirantes y los hasta ahora ciudadanos dotados, son objeto de exclusión como «haitianos». Pareciera que la frontera que sus antepasados cruzaron hace años se hubiera replegado en forma de fantasma legal/ burocrático y, metafóricamente hablando, los hubiera cruzado nuevamente. La «frontera» es desterritorializada, proyectada a través del territorio dominicano «dondequiera que se encuentren los controles selectivos» (Balibar, 2002:34). 
Dichas «fronteras interiores» pueden ser tan evidentes como los puntos de control en las principales vías o tan sutiles como los mecanismos para solicitar servicios de salud pública, abrir una cuenta bancaria, acceder a prestaciones de desempleo y pensiones u obtener tarjetas nacionales de identificación (Ajana, 2013:57).

Esa tecnología legal/forense apunta a una segunda forma en la que el exclusionismo antihaitiano de hoy combina el atavismo moral con el progreso técnico: el despojo de identidad es una práctica de la ley y las tecnologías computarizadas del almacenamiento, recuperación e intercambio de datos. Si bien una vez los descendientes de haitianos sufrieron discriminación arbitraria, carente de fundamento jurídico claro, hoy el exclusionismo antihaitiano se encuentra cada vez más codificado legalmente, tecnológicamente vigilado y rigurosamente aplicado. Incluso la imagen de una huella digital que conforma el logotipo actualizado de la Junta Central Electoral (véase http://jce.gob.do/) parece presumir un compromiso con el aseguramiento de la biopolítica oficial. Los agentes del nuevo exclusionismo no son hombres que blanden escopetas a caballo, sino burócratas instalados en cubículos fuera de la vista pública.

Por último, el caso en cuestión merece ser estudiado como un cuento cauteloso para los derechos humanos internacionales. Mediante una serie de leyes, veredictos de tribunales superiores y medidas burocráticas internas en la República Dominicana, los nacionalistas dominicanos han contrarrestado una estrategia legal pro-derechos con una juridicalización reaccionaria del exclusionismo anti-haitiano. Nuestro temor es que los proponentes de derechos liberales estén apartando la atención del público de lo que es cualitativamente nuevo en el actual exclusionismo antihaitiano oficial, al destacar las expulsiones masivas y otros casos de violencia, intimidación o fuerza arbitraria, como rasgos principales del antihaitianismo dominicano. Nadie puede negar que tales actos de odio sean chocantes. Sin embargo, los liberales también deberían constatar no sólo la antigüedad del prejuicio antihaitiano sino también la novedad de los medios en que se despliega la República Dominicana. La seña principal de lo nuevo en esta situación consiste en la aparente paradoja de que los haitianos y los descendientes de haitianos son más libres de desplazarse por el país aun cuando su movilidad socioeconómica se halla más rígidamente contenida. Ahora libres de alejarse de las plantaciones de azúcar tan fácilmente como llegan (Verité, 2012:50), los descendientes de haitianos son, no obstante, incapaces de escapar de la sombra de los muros cibernéticos sociales a través 
de los cuales la ley y la burocracia los incluyen en una segunda clase, dentro de la condición de forasteros.

Agradecimientos: Damos las gracias a Karen Richman y Henry Carey por haber convocado el taller en la Universidad Estatal de Georgia sobre Haití-República Dominicana (19 de mayo de 2016), en el que se presentó una versión preliminar de este documento, así como al ponente Ernesto Sagás y a los otros participantes del taller por sus sugerencias detalladas y de apoyo para la mejora del mismo. De igual modo, reconocemos el magnífico trabajo de traducción que hizo Milena Almira del inglés. Los firmantes son, salvo que se indique de manera debida, los autores originales del contenido de este documento y son responsables también de todos los errores u omisiones que puedan quedar.

\section{Referencias}

Acento (26 de octubre de 2015), «DXD en audiencia CIDH: Demanda acuerdo solucionar problemática desnacionalización», en http://acento.com.do/2015/actualidad/ 8294727-dxd-en-audiencia-cidh-demanda-acuerdo-solucionar-problematica-dedesnacionalizacion/

(8 de enero de 2016), «ACNUR reitera que existen 133770 personas apátridas en la RD, y que podrían ser más», en http://acento.com.do/2016/actualidad/8313829acnur-reitera-que-existen-133770-personas-apatridas-en-la-rd-y-que-podrian -ser-mas/ Agamben, Giorgio (1998), Homo Sacer: Sovereign Power and Bare Life, Stanford, Stanford University Press.

Ajana, Btihaj (2013), Governing through Biometrics: The Biopolitics of Identity. Houndmills, Basingstoke, UK, Palgrave Macmillan.

Amnesty International (2013), «Dominican Republic Must Retract Ruling that Could Leave Thousands Stateless», en http://www.amnesty.org/en/news/dominicanrepublic-must-retract-ruling-could-leave-thousands-stateless-2013-10-18

Balibar, Etienne (2002), Politics and the Other Scene, London, Verso.

Baluarte, David C. (2006), "Inter-American Justice Comes to the Dominican Republic: An Island Shakes as Human Rights and Sovereignty Clash», American University Human Rights Brief, 2(13), pp. 25-28, 38, en http://www.wcl.american.edu/hrbrief/ 13/2baluarte.pdf?.rd=1

International Human Rights Law Clinic (2002), Unwelcome Guests: A Study of Expulsions of Haitians and Dominicans of Haitian Descent from the Dominican Republic to Haiti. 
Berkeley, Boalt Hall School of Law, University of California, en http://www.law. berkeley.edu/files/Unwelcome_Guests.pdf

Campbell, Timothy \& Adam Sitze (2013), "Introduction: Biopolitics: An Encounter», in Biopolitics: A Reader, pp. 3-40, Durham, North Carolina, Duke University Press.

Centro Cultural Domínico-Haitiano (1997), Análisis de la situación inmigrantes haitianos en la República Dominicana, Santo Domingo, CCDH.

Cedeño, Carmen (1992), "La nacionalidad de los descendientes de haitianos nacidos en la República Dominicana», en Lozano, Wilfredo (ed.), La cuestión haitiana en Santo Domingo: Migración internacional, desarrollo y relaciones inter-estatales entre Haití y República Dominicana, pp. 137-143, Santo Domingo, FLACSO-Programa República Dominicana y Centro Norte-Sur, Universidad de Miami.

Díaz, Juan Bolívar (29 de octubre de 2011), «CE suspende su cgenocidio civil», Hoy, en http://hoy.com.do/jce-suspende-su-«genocidio-civil»/

Ministerio de relaciones exteriores (10 de enero de 2016), "Cancillería coordina segunda reunión de la JCE con la sociedad civil y organismos internacionales», Diario Libre, en http://www.diariolibre.com/noticias/cancilleria-coordina-segunda-reunionde-la-jce-con -la-sociedad-civil-y-organismos-internacionales-GJ2391190

120

El Caribe (1 de diciembre de 2015), "Rosario admite en una circular que hay presiones», en http://www.elcaribe.com.do/2015/12/01/rosario-admite-una-circular-quehay-presiones

Espinal, Rosario (1 de julio de 2015), «El avispero con los haitianos», Hoy, en http://hoy. com.do/el-avispero-con-los-haitianos/

Faxas, Natalí (12 de enero de 2016), «52 665 extranjeros no han retirado su carné migratorio", El Caribe, en http://www.elcaribe.com.do/2016/01/12/52665-extranjeros -han-retirado-carne-migratorio

Foucault, Michel (1978), The History of Sexuality, Volume I: An Introduction, New York, Vintage Books.

(1980), "The Confession of the Flesh», en Colin Gordon (ed.), Power/Knowledge: Selected Interviews and Other Writings, 1972-1977, pp. 194-228, New York, Pantheon Books.

(2003), "Society Must Be Defended»: Lectures at the College de France, 1975-1976, New York: Picador.

(2007), Security, Territory, Population: Lectures at the College de France, 1977-1978, New York, Palgrave Macmillan.

(2008), The Birth of Biopolitics: Lectures at the Collège de France, 1978-79, Hampshire, Palgrave Macmillan. 
Garcia, Michelle (2006), «No Papers, no Rights», Amnesty International Magazine, otoño 2006, pp. 20-23, 30.

Granne, Michael (2001), Expelled: Mass Expulsions of Individuals of Haitian Descent from the Dominican Republic, New York, Witness Productions.

Hamann, Trent H. (2009), «Neoliberalism, Governmentality and Ethics», Foucault Studies, 1(6), pp. 37-59.

Hintzen, Amelia (2016), «Cultivating Resistance: Haitian-Dominican Communities and the Dominican Sugar Industry» (Tesis doctoral), Departamento de Historia, Universidad de Miami.

Human Rights Watch (2015), We are Dominican. Arbitrary Deprivation of Nationality in the Dominican Republic, en https://www.hrw.org/report/2015/07/01/we-are-dominican/ arbitrary-deprivation-nationality-dominican-republic

Katz, Jonathan M. (13 de enero de 2016), «In Exile: Deportations and Violence Have Driven Tens of Thousands of People of Haitian Descent from their Homes in the Dominican Republic-While the World is Silent», New York Times, en http://www. nytimes.com/2016/01/17/magazine/haitians-in-exile-in-the-dominicanrepublic.html? $\mathrm{r}=0$

Lawyers Committee for Human Rights (1991), A Childhood Abducted: Children Cutting Sugar Cane in the Dominican Republic, New York, Lawyers Committee for Human Rights.

Lechte, John \& Saul Newman (2013), Agamben and the Politics of Human Rights: Statelessness, Images, Violence, Edinburgh, Edinburgh University Press.

Lippmann Mazzaglia, Natalia \& Pedro F. Marcelino (2014), «Migratory Policy as an Exclusionary Tool: The Case of Haitians in the Dominican Republic», Laws, vol. 3, núm. 1, pp. 163-178.

Martínez, Samuel (2012), «Allegations Lost and Found: The Afterlife of Dominican Sugar Slavery», Third World Quarterly, 10(33), pp. 1855-1870.

(2014a), «The Price of Confrontation: International Retributive Justice and the Struggle for Haitian-Dominican Rights", in George Andreopoulos \& Zehra Arat (eds.), The Uses and Misuses of Human Rights: A Critical Approach to Advocacy, pp. 89-115, New York, Palgrave.

(12 de marzo de 2014b), "Anti-Haitian Exclusionism in the Dominican Republic: A Biopolitical Turn?», College of the Holy Cross, Carson Lecture Series, en https://www.youtube.com/watch? $=$ =TLLUztLPJkk

Movimiento por un Registro Libre de Discriminación (3 de noviembre de 2011), «La Circular 32/11 es un paso insuficiente», nota de prensa. 
OBMICA (2015), "Arreglos institucionales para la implementación del PNRE», Boletín informativo OBMICA, 2(5), en http://obmica.org/images/Publicaciones/Boletines/ boletin\%200BMICA-junio\%202015\%20FINAL.pdf

Oficina Nacional de Estadística (2013), Primera encuesta nacional de inmigrantes en la República Dominicana (Informe general ENI-2012), Santo Domingo, ONE.

Ong, Aihwa (1999), Flexible Citizenship: The Cultural Logics of Transnationality, Durham, North Carolina, Duke University Press.

Petrozziello, Allison J., Amelia Hintzen y Juan Carlos González Díaz (2014), Género y el riesgo de apatridia para la población de ascendencia haitiana en los bateyes de la Republica Dominicana. Santo Domingo, OBMICA, en http://obmica.org/index.php/ publicaciones/libros/92-genero-y-el-riesgo-de-apatridia-para-la-poblacion -de-ascendencia-haitiana-en-los-bateyes-de-la-republica-dominicana

República Dominicana (27 de agosto de 2004), «Ley General de Migración, No. 285-04», Gaceta Oficial, 10291, pp. 5-46, en http://docs.republica-dominicana.justia.com/ nacionales/leyes/ley-285-04.pdf

República Dominicana, Congreso Nacional (2014), «Ley No.169-14», en http://www.sipi. siteal.org/sites/default/files/sipi_normativa/ley_ndeg169_de_2014_regularizacion_y_ naturalizacion_de_extranjeros_en_el_registro_civil_dominicano.pdf

República Dominicana, Ministerio de Interior y Policía (2016), «Ministro Interior y director Migración analizan componentes del Plan de Regularización», en http:// www.mip.gob.do/index.php/noticias/item/ministro-interior-y-director-migracionanalizan-componentes-del-plan-nacional-de-regularizacion

República Dominicana, Oficina de la Presidencia (2013), "Decreto No. 327-13», en http://www.refworld.org/pdfid/52fcaf984.pdf

República Dominicana, Tribunal Constitucional (2013), «Sentencia TC/0168/13», en http://noticiasmicrojuris.files.wordpress.com/2013/10/sentenciatc0168-13-c.pdf

République d'Haïti (2014), "Arrêté accordant à toute personne dépourvue d'acte de naissance, un délai de cinq (5) ans pour faire régulariser son état civil», Le Moniteur, núm. 10.

Riveros, Natalia, Carlos Abaunza, Adriana Salcedo y Eddy Tejeda (2015), Estado del Arte de las Migraciones que Atañen a la Republica Dominicana 2014 (Informe), Santo Domingo, OBMICA, en http://obmica.org/index.php/publicaciones/informes/ 126-estado-del-arte-de-las-migraciones-que-atanen-a-la-republica-dominicana $-2014$

Verite (2012), Research on Indicators of Forced Labor in the Supply Chain of Sugar in the Dominican Republic, en https://www.verite.org/wp-content/uploads/2016/11/ 
Research-on-Indicators-of-Forced-Labor-in-the-Dominican-Republic-SugarSector_9.18.pdf

Virno, Paolo (2004), A Grammar of the Multitude: For an Analysis of Contemporary Forms of Life, Los Angeles, Semiotext(e).

Waas, Laura van (2007), "The Children of Irregular Migrants: A Stateless Generation?», Netherlands Quarterly of Human Rights, 3(25), pp. 437-458. 